\title{
EL CAMBIO CLIMÁTICO COMO PROBLEMA Y EL DIÁLOGO SOCIAL COMO SOLUCIÓN
}

Gerard Jori

Departamento de Geografía Humana Universidad de Barcelona

\section{RESUMEN}

El cambio climático constituye uno de los mayores desafíos a los que se enfrenta la humanidad. De forma inequívoca, el planeta es actualmente más cálido que tres décadas atrás, y continuará calentándose durante los próximos decenios. Tal variación de la temperatura media mundial puede desencadenar unos efectos ecológicos, económicos y sociales potencialmente inquietantes, por lo que la lucha contra el cambio climático ha pasado a ocupar un lugar prioritario en la lista de objetivos científicos y en la agenda política. En este artículo se argumenta la necesidad de introducir mecanismos de participación ciudadana en la definición de estrategias para hacer frente al cambio climático. Este problema ambiental encierra tal diversidad de dimensiones e incertidumbres que es preciso integrar todas las formas de conocimiento para proponer soluciones coherentes y eficaces. El saber que atesora el ciudadano es complementario al del experto e igualmente necesario para combatir el cambio climático, pues aporta elementos capaces de desvelar variables que los científicos y políticos suelen pasar por alto.

Palabras clave: cambio climático, percepción ambiental, diálogo social, participación ciudadana.

\section{RESUMÉ}

Le changement climatique constitue un des principaux défis auxquels l'humanité doit faire face. Sans équivoque, la planète est actuellement plus chaude que trente années plus tôt et elle continuera à se réchauffer pendant les pro- 
chaines décennies. Cette variation de la température moyenne mondiale peut déchaîner des conséquences écologiques, économiques et sociales qui sont potentiellement inquiétantes, ce qui fait que la lutte contre le changement climatique soit une priorité dans la liste des objectifs scientifiques et de l'ordre du jour politique. Cet article argumente la nécessité d'introduire des mécanismes de participation citoyenne dans la définition des stratégies pour faire face au changement climatique. Ce problème environnemental renferme une telle diversité de dimensions et d'incertitudes qu'il est nécessaire d'intégrer toutes les formes de connaissance pour proposer des solutions cohérentes et efficaces. Le savoir citoyen est complémentaire à celui de l'expert et également nécessaire pour lutter contre le changement climatique parce qu'il est capable de faire affleurer des variables que les scientifiques et les politiciens ont tendance à ignorer.

Mots clefs: changement climatique, perception environnementale, dialogue social, participation citoyenne.

\section{INTRODUCCIÓN}

Las sociedades actuales se enfrentan a un problema ambiental -el cambio climático- que no tiene parangón en la historia de la humanidad. Históricamente, civilizaciones como la pascuense, maya o anasazi han sucumbido ante situaciones de colapso ambiental, pero siempre se trató de catástrofes localmente limitadas. En cambio, la alteración del clima planetario motivada por causas antrópicas puede desencadenar unos impactos ecológicos, económicos y sociales capaces de trastornar las formas de vida en el conjunto del planeta. La magnitud del problema es tal, que el cambio climático se ha convertido en una de las cuestiones más debatidas en la literatura científica, la práctica política y los medios de comunicación. Las actitudes negacionistas, tan en boga hace apenas unos años, han ido progresivamente cayendo en el descrédito a medida que aumentaba el conocimiento científico del fenómeno y se multiplicaban las evidencias empíricas del mismo, y parece que por fin se instala un consenso generalizado acerca del carácter inequívoco del cambio climático.

Al mismo tiempo, han ido surgiendo numerosas iniciativas políticas que, con mayor o menor fortuna, tratan de hacer frente a la amenaza. Aunque la diversidad de estas iniciativas es extraordinaria, se advierte un sesgo bastante acentuado hacia las medidas de índole tecnológica, orientadas, fundamentalmente, a la reducción de las emisiones de gases de efecto invernadero mediante la sustitución de las fuentes de energía fósil y el aumento de la eficiencia energética. Sin negar la relevancia de este tipo de acciones, es incuestionable que la mitigación del cambio climático y la adaptación de las sociedades a las nuevas condiciones 
ambientales son retos que exceden la esfera energética, por lo que requerirán mucho más que el reemplazo de unas tecnologías por otras. Los problemas complejos demandan soluciones complejas, de modo que, desde nuestro punto de vista, también será necesario redefinir muchos de los fundamentos de los actuales modelos productivos, territoriales y culturales. En otras palabras, la situación de urgencia histórica en la que nos encontramos reclama una transición hacia pautas de vida más acordes con las leyes de la naturaleza. En buena medida, el éxito de dicho proceso de cambio dependerá de la capacidad de las autoridades políticas y de la comunidad científica para movilizar la acción individual y colectiva, siendo así que todo lo tocante a la percepción social del cambio climático adquiere una importancia decisiva.

En este trabajo se tratará de mostrar que el conocimiento de las actitudes sociales ante el cambio climático posee un valor extraordinario de cara a responder con estrategias de «altas miras» al reto que representa esta problemática ambiental. Nuestra hipótesis es que el entendimiento de la percepción del ciudadano acerca de esta cuestión supone, al menos, tres grandes potencialidades. En primer lugar, la información perceptual permite adecuar las políticas contra el cambio climático a los patrones de comportamiento de la sociedad relativos a una gran diversidad de aspectos que resultan significativos para la resolución del problema: alimentación, movilidad, etc. En segundo lugar, es importante saber cómo se percibe el cambio climático para detectar aquellos asuntos en los que existan lagunas o creencias populares erróneas. Sólo de este modo será posible determinar qué mensajes hay que difundir entre la sociedad para aclarar los temas que resulten más oscuros o erradicar las equivocaciones más comunes. Finalmente, conviene conocer las actitudes y opiniones de los individuos, porque el saber ciudadano, basado, fundamentalmente, en las experiencias vividas, puede resultar de gran utilidad a la hora de definir políticas eficaces contra el calentamiento global. Es decir, no hay que menospreciar ni minusvalorar el conocimiento que atesoran los ciudadanos sobre esta materia, ya que, en ocasiones, este capital cognitivo podría producir resultados más fructuosos que los cosechados hasta el momento por técnicos, científicos y políticos.

Las páginas que siguen tratarán de confirmar o rechazar la validez de esta tercera suposición, para lo que se contemplarán cuatro apartados. En el primero, se mostrarán muy sucintamente las principales evidencias científicas del calentamiento global y la potencial gravedad de los impactos que puede desencadenar en el futuro. En el segundo apartado se explicarán algunas respuestas institucionales al cambio climático y se argumentará que una de sus principales limitaciones reside en la ausencia de planteamientos auténticamente democráticos que atiendan a las aportaciones ciudadanas para afrontar el problema. A 
continuación, se abordará la percepción social del cambio climático, poniendo de relieve, primeramente, el papel de los medios de comunicación en el fortalecimiento de la concienciación y conocimientos de la población al respecto, y en segundo lugar, los rasgos esenciales de la representación social del problema en Europa, España y Cataluña. Por último, se mostrará el valor de las propuestas ciudadanas para combatir el cambio climático explicando algunos resultados de una consulta que se realizó en diciembre de 2007.

\section{PRINCIPALES EVIDENCIAS Y EFECTOS DEL CAMBIO CLIMÁTICO}

El Cuarto Informe IPCC, que constituye, de largo, el documento más amplio, completo y riguroso sobre el estado y evolución del sistema climático mundial, define el cambio climático como aquella alteración «en el estado del clima identificable [...] a raíz de un cambio en el valor medio y/o en la variabilidad de sus propiedades, y que persiste durante un periodo prolongado, generalmente cifrado en decenios o en periodos más largos» (IPCC, 2007: 30). Para los autores del informe, el término «cambio climático» denota, por tanto, todo cambio experimentado por el clima a lo largo de periodos dilatados de tiempo y con independencia de si es debido a causas naturales o a la actividad humana.

La variabilidad es uno de los atributos esenciales del comportamiento del sistema climático en general, y de la atmósfera en particular. Como su nombre indica, cualquier variable del clima presenta un comportamiento dinámico a cualquier escala espacial y temporal que se considere. Tomemos por caso la distribución geográfica de los valores medios anuales de dos de los elementos climáticos más decisivos: temperatura y precipitación. La variación de la temperatura media anual en la superficie de la Tierra va de $-57,8^{\circ} \mathrm{C}$ en un punto de la Antártida a 34,4 $4^{\circ} \mathrm{C}$ en la localidad etíope de Dalol (Martín-Vide, 1999: 67), mientras que la cantidad media anual de precipitación oscila entre prácticamente $0 \mathrm{~mm}$ en el desierto de Atacama (Chile) y $11.455 \mathrm{~mm}$ en el hawaiano monte Waialeale (Martín-Vide, 1999: 123). Pero las variables climáticas no sólo varían en el espacio, sino también en el tiempo, y ello no tiene por qué reflejar una tendencia en su comportamiento temporal. Así, por ejemplo, los valores medios mensuales de presión atmosférica registrados en Barcelona durante los años 1780-1989 presentan contrastes extraordinariamente acusados, con un mínimo de 999,4 hPa en mayo de 1862 y un máximo de 1.030,5 hPa en febrero de 1918 (Rodríguez et al., 2001: 1.701). Tal variabilidad no evidencia cambio climático alguno sino, simplemente, el funcionamiento natural -o sea, dinámico- de la atmósfera.

Otra cosa bien distinta son las frecuentes alteraciones climáticas que han tenido lugar a lo largo de la historia geológica del planeta como consecuencia de 
factores no antrópicos, tales como las variaciones de la constante solar o de los parámetros orbitales del planeta. Las glaciaciones cuaternarias, que constituyen los ejemplos mejor estudiados de este tipo de cambios, comportaron abruptas modificaciones de la faz de la Tierra, siendo de sobra conocidas las hipótesis que vinculan la inestabilidad climática durante el último periodo glacial con el desarrollo de la cultura humana y la expansión geográfica de nuestra especie (v. e.g. Sauer 2005 [1955]: 417-421). Este tipo de variaciones en el comportamiento del clima se ajusta a la definición de «cambio climático» que ofrece el Cuarto Informe IPCC (2007), dado que representan modificaciones del estado del clima, se producen durante periodos de tiempo prolongados y responden a la variabilidad natural del sistema climático. Por tanto, la novedad de las actuales alteraciones climáticas no reside tanto en el hecho de que se produzcan, como en la causa que las ocasiona.

Numerosas evidencias científicas demuestran que desde los inicios de la Revolución Industrial, la concentración atmosférica de dióxido de carbono $\left(\mathrm{CO}_{2}\right)$ y de otros gases de efecto invernadero (GEI), tales como el metano $\left(\mathrm{CH}_{4}\right)$ y el óxido nitroso $\left(\mathrm{N}_{2} \mathrm{O}\right)$, ha aumentado de forma muy apreciable como consecuencia de la quema de ingentes cantidades de combustibles fósiles, aunque también se señalan otras causas como la expansión de determinadas actividades agrícolas y ganaderas. Los GEI son gases con una gran capacidad para absorber la radiación infrarroja emitida por la Tierra, por lo que un aumento de su concentración troposférica implica un incremento de la retención de calor en el sistema conformado por la superficie terrestre y la troposfera. Las emisiones anuales de $\mathrm{CO}_{2}$, que representan el principal GEI antropogénico, han crecido en aproximadamente un 80 por ciento entre 1970 y 2004, pasando de 21 a 38 gigatoneladas (Gt). Su concentración en la atmósfera ha aumentado de $280 \mathrm{ppm}$ en época preindustrial a 379 ppm en 2005, como también lo ha hecho la del $\mathrm{CH}_{4}, \mathrm{~N}_{2} \mathrm{O}$ y numerosos halocarbonos (IPCC, 2007: 36-38). A resultas de ello cabe esperar un incremento de la temperatura media mundial acompañado de un cambio en la irradiación neta (forzamiento radiativo).

Los datos al respecto no ofrecen dudas de que este efecto ha tenido lugar, pues según el Cuarto Informe IPCC (2007: 30) la temperatura media de la Tierra ha aumentado en $0,74^{\circ} \mathrm{C}$ durante el siglo que va de 1906 a 2005. Dicho incremento térmico es consistente, de un lado, con la reducción observada de la cubierta de nieve y hielo, y de otro, con el aumento del promedio mundial del nivel del mar, que en la última década ha crecido a un ritmo de 3,1 $\mathrm{mm}$ anuales. A diferencia de otros cambios climáticos, las alteraciones actuales se están desarrollando a un ritmo relativamente rápido. No obstante, su principal particularidad reside en el agente que las está originando: el hombre. El forzamiento 
radiativo causado desde 1750 por los aumentos conjuntos de $\mathrm{CO}_{2}, \mathrm{CH}_{4}$ y $\mathrm{N}_{2} \mathrm{O}$ antropogénicos, evaluado en $+2,3 \mathrm{~W} / \mathrm{m}^{2}$, es muy superior al estimado por el efecto de los cambios en la irradiación solar $\left(+0,12 \mathrm{~W} / \mathrm{m}^{2}\right)$ (IPCC, 2007: 38). En consecuencia, las actividades antrópicas constituyen la causa de las alteraciones en el sistema climático mundial que vienen produciéndose desde los albores de la industrialización, y con especial intensidad desde mediados de los años sesenta de la pasada centuria.

Ya han podido documentarse algunos efectos del aumento de la temperatura en los sistemas físicos y biológicos (IPCC, 2007: 31-33). Asimismo, se han aventurado otros impactos que el cambio climático podría desencadenar en el futuro, tanto a escala mundial como por grandes conjuntos regionales (IPCC, 2007: 4754). Pese a que algunos de estos efectos se avecinan ventajosos para el hombre, como es el caso, por ejemplo, de un mayor rendimiento agrícola en determinados entornos fríos, la inmensa mayoría resultarán sumamente contraproducentes. Así, por mencionar únicamente algunos de los impactos cuya probabilidad de ocurrencia se evalúa en más del 90 por ciento, cabe esperar un aumento de las plagas, una disminución de la calidad del agua, una reducción de la calidad de vida en las áreas cálidas y un mayor riesgo de contraer enfermedades infecciosas, respiratorias y dérmicas. Además, se espera que dos de las regiones más vulnerables del planeta sean África y las grandes áreas deltaicas de Asia, que ya experimentan graves problemas estructurales y se encuentran entre los sectores más empobrecidos del mundo. La inestabilidad social que el cambio climático puede originar en esas regiones acabaría seguramente trasladándose al resto de países y repercutiría, de forma especialmente intensa, en los más desarrollados.

\section{LAS LIMITACIONES DE LAS RESPUESTAS INSTITUCIONALES}

Dada la magnitud de los impactos que el cambio climático puede desencadenar, éste se ha convertido en un vector importante de la reflexión y planificación estratégica en ámbitos muy diversos, que van desde el turismo (Gómez Martín, 2004) a la epidemiología (Githeko et al., 2000), pasando por el patrimonio histórico (Zanirato, 2008), el riego agrícola (Rodríguez Díaz et al., 2006) o la gestión forestal (Rosas, 2002). Asimismo, desde hace unos años se asiste a una auténtica proliferación de programas institucionales para hacer frente al cambio climático, siendo así que puede afirmarse que éste ha cobrado una entidad plenamente política y social. Un aspecto importante que estos programas han debido asumir es el carácter inevitable del cambio climático. Debido a la gran inercia del efecto invernadero provocado por los GEI, el planeta continuará calentándose a pesar de que se reduzcan sustancialmente las emisiones de esos gases, por lo que en sentido estricto, el cambio climático no tiene solución. Es por ello que, desde 
hace ya unos años, la literatura especializada suele traer a colación dos conceptos alternativos, aunque complementarios entre sí, como son los de «mitigación» y «adaptación» (v. e.g. Kane et al., 2000). Así, las respuestas más pragmáticas y realistas al cambio climático contemplan, de un lado, acciones orientadas a atenuar su intensidad mediante la reducción de las emisiones de GEI; y de otro, estrategias dirigidas a minimizar la vulnerabilidad de las sociedades con el objetivo de amortiguar los impactos del calentamiento global.

La lógica del funcionamiento de la acción colectiva es otro aspecto que conviene tener en cuenta a la hora de definir respuestas al cambio climático. Según el modelo ya clásico del estadounidense Mancur Olson (1971), los individuos sólo optan por participar en un grupo de intereses para la consecución de un bien público cuando los beneficios esperados de su participación superan a los costes. A medida que aumenta el tamaño del grupo, la percepción sobre la importancia de la participación propia disminuye, mientras que los costes se mantienen estables. De este modo, la tesis de Olson es que cuando existen asociaciones muy grandes, las tentaciones para no participar en la conquista del objetivo, esperando que otros lo hagan, son mayores, proliferando, entonces, las actitudes de «polizón» (free-rider). La aplicación de este modelo al caso concreto de las respuestas al cambio climático ofrece dos conclusiones interesantes. La primera es que los actores sociales tenderán a preferir la adaptación a la mitigación, ya que aquélla acarrea unos costes inferiores para las generaciones actuales. La segunda -y más importante- es que al tratarse de un objetivo que atañe al mundo entero, los incentivos para no cooperar son muy grandes, lo que determinaría un aumento del número de «polizones» que, bajo la perspectiva de la maximización de su utilidad, no iniciarían estrategias para combatir el cambio climático, esperando que otros lo hagan por ellos. En este sentido, se ha sugerido que uno de los motivos que explican que Europa tienda a mostrar mayor predisposición que Estados Unidos a afrontar el cambio climático es, precisamente, que en el balance costesbeneficios este último país sería un perdedor neto (Sustein, 2006: 207).

Creemos que ambas ideas contribuyen a explicar el fracaso -relativo- de los más de veinte años de negociación y concertación de acciones para hacer frente al cambio climático. No obstante, como se tratará de mostrar más adelante, el principal inconveniente reside en la ausencia de planteamientos auténticamente democráticos en la definición de esas vías de acción; esto es, de enfoques que atiendan a las actitudes y propuestas de la ciudadanía para combatir la amenaza que supone el calentamiento global.

A escala internacional, pueden destacarse tres grandes foros o instrumentos de cooperación: la Convención Marco de Naciones Unidas sobre el Cambio Climático (CMNUCC), el Protocolo de Kioto (PK) y el Panel Intergubernamental 
sobre Cambio Climático (IPCC, por sus siglas en inglés) (Barros, 2006: 155163). La CMNUCC fue adoptada en 1992 durante la Conferencia de Rio de Janeiro y su negociación anunció muchos de los problemas que, hasta día de hoy, han venido perturbando la lucha contra el cambio climático; ante las reticencias de algunos países a restringir sus emisiones de GEI, el documento finalmente aprobado eludió las medidas concretas y no pasó de los aspectos meramente declarativos.

Con todo, durante la Tercera Conferencia de las Partes de la CMNUCC, celebrada en Kioto en 1997, se acordó un protocolo para que los países desarrollados reduzcan sus emisiones de GEI en un 5,2 por ciento en relación a los niveles de 1990 y durante el periodo 2008-2012 (CMNUCC, 1998). Para facilitar el cumplimiento de los compromisos, el PK estableció los llamados «mecanismos de flexibilización», entre los cuales destaca la creación de un mercado de carbono que convierte en comercializables las cuotas de emisiones atmosféricas de $\mathrm{CO}_{2}$. Ciertamente, este mecanismo ofrece alguna flexibilidad a la hora de organizar la transición a los objetivos del PK. Sin embargo, se trata de un sistema que permite eludir los compromisos medioambientales mediante una tergiversación perversa del principio «quien contamina paga» por el de «quien paga contamina». De todos modos, las expectativas suscitadas por el PK continuarán siendo una simple quimera mientras Estados Unidos - principal emisor mundial- y China -futuro gran emisor- no adquieran compromisos sólidos para reducir sus emisiones contaminantes.

El IPCC es un organismo independiente, consultivo, de carácter científico y auspiciado por la Organización Meteorológica Mundial (OMM) y el Programa de Naciones Unidas para el Medio Ambiente (PNUMA). Creado en 1988, su principal cometido no reside en la investigación científica, sino en la elaboración de informes periódicos sobre la base de publicaciones indexadas. Ya han aparecido cuatro de estos informes (1990; 1995; 2001; 2007), considerados como referencias obligadas para el conocimiento del estado y evolución del clima. En el último, elaborado entre 2003 y 2007, han participado cerca de 450 autores principales, 800 autores contribuyentes y 2.500 revisores. En realidad, se trata de tres informes en uno: el primero trata de los aspectos físicos del cambio climático; el segundo, de sus impactos sociales y naturales; y el tercero, de las políticas para hacer frente a esta problemática ambiental.

La lucha contra el cambio climático no sólo se orquesta a escala internacional, sino que desde ámbitos más reducidos también se están realizando esfuerzos al respecto. Desde 2005, la Unión Europea vehicula su estrategia a través del llamado Segundo programa europeo sobre cambio climático (European Commission, 2003), documento que hace especial hincapié en tres aspectos: la reducción de 
las emisiones vinculadas a los transportes, el fomento de las innovaciones tecnológicas que contribuyan a la eficiencia energética y la adaptación de la sociedad a las nuevas condiciones climáticas, objetivo éste que ha merecido la publicación de un Libro verde (Comisión Europea, 2007). En España, se encuentra vigente una Estrategia española de cambio climático y energía limpia (Ministerio de Medio Ambiente, 2007) que persigue como objetivo fundamental asegurar el cumplimiento de los compromisos internacionales adquiridos en materia de reducción de emisiones. El documento incluye un «Plan de medidas urgentes» en el que cobran especial relevancia las acciones orientadas a asegurar una mayor eficiencia energética, particularmente en el sector de los transportes. Finalmente, debe señalarse que los gobiernos autonómicos también han impulsado medidas para afrontar el cambio climático. En Cataluña, por ejemplo, existe un Pla marc de mitigació del canvi climàtic (Departament de Medi Ambient i Habitatge, 2008) que, de todos los documentos comentados, constituye, de largo, el más riguroso y el que establece de forma más pormenorizada las distintas acciones a desarrollar. Además, este programa de actuaciones ha sido elaborado a partir de un proceso participativo en el que expertos, ciudadanos y una amplia miríada de entidades -empresas, asociaciones, ayuntamientos, sindicatos, etc.- han podido formular cerca de mil propuestas.

Pese a la existencia de iniciativas laudables como ésta, creemos que las respuestas institucionales al cambio climático no han sabido movilizar suficientemente al conjunto de la sociedad, desaprovechando, de este modo, la posibilidad de concertar acciones entre los distintos agentes sociales. Como señalan Silvio O. Funtowicz y Jerry R. Ravetz (e.g. 1991; 1999), los problemas ambientales se caracterizan por su complejidad intrínseca, no tanto por ser complicados, como por encerrar una gran pluralidad de incertidumbres, dimensiones y perspectivas legítimas que en modo alguno pueden ser verificadas en su totalidad a través de los mecanismos tradicionales -normales- de la ciencia y la política. Para aprehender la diversidad de atributos interconectados y puntos de vista que abarcan esos problemas y proponer, en consonancia, soluciones coherentes a los mismos, es preciso integrar el conocimiento no experto -incluyendo valores y creencias- en los procesos de investigación y gestión ambiental. De este modo, Funtowicz y Ravetz proponen la ciencia posnormal como vía de aproximación a los problemas ambientales. El modelo de argumentación ya no es la deducción formalizada, sino el diálogo interactivo, que huye de dogmatismos estériles para hacer aflorar la pluralidad de conexiones e integrar el mayor número de intereses en juego. Se presupone que el conocimiento que atesora el ciudadano es complementario al del experto e igualmente necesario y válido para la definición de estrategias políticas eficaces, ya que aporta un saber cualitativo basado en las 
vivencias cotidianas y capaz de desvelar variables, relaciones y marcos interpretativos que los expertos suelen pasar por alto.

Dado que el conjunto de la ciudadanía es acreedora de un capital cognitivo que resulta indispensable para combatir amenazas como el cambio climático, los sistemas de investigación científica y de decisión política deben afrontar el doble reto de superar la actual atomización del saber y definir metodologías de evaluación y acción que permitan agregar conocimientos, coordinar esfuerzos y consensuar respuestas a los problemas. Desde la filosofía de la ciencia ya se ha argumentado que ésta no posee ninguna característica intrínseca que la haga necesariamente superior a otras formas de conocimiento (Feyerabend, 2002 [1975]). Y desde la filosofía política se ha razonado la necesidad de evitar que la democracia se convierta en un simple acto de delegación de los gobernados a los gobernantes, para erigirse en una forma política derivada de un proceso comunicativo orientado a la consecución de acuerdos consensuales en la toma de decisiones colectivas (Habermas, 1988). A la vista de ello, ¿por qué no preguntar al ciudadano qué opina del cambio climático? ¿Cuáles son sus inquietudes y expectativas al respecto? ¿Qué medidas adoptaría para hacer frente a esta problemática planetaria? Los siguientes apartados tratarán de mostrar el valor que poseen la percepción y actitudes sociales sobre el cambio climático para afrontar este desafío de manera adecuada.

\section{PERCEPCIÓN Y ACTITUDES DE LA SOCIEDAD ANTE EL CAMBIO CLIMÁTICO}

Una de las líneas de investigación geográfica que en los años setenta parecía particularmente prometedora, pero que desgraciadamente no ha tenido la continuidad esperada, es el estudio de la percepción del medio y su engarce con el comportamiento geográfico. El fundamento de este objeto de investigación reside en el descubrimiento de que el individuo no se comporta en función de cómo es la realidad, sino de la imagen que de la misma se ha formado, por lo que si se quiere comprender la acción humana sobre la superficie terrestre, asunto al que tradicionalmente la geografía ha prestado una gran atención, resulta indispensable atender a los mapas espaciales formados en la mente de cada individuo a partir de sus vivencias personales (Capel, 1973: 58-59). El estudio de la percepción ambiental encierra varias facetas, siendo la percepción climática y meteorológica una de las más complejas. Aunque faltan trabajos sistemáticos sobre esta materia, algunos estudios han puesto de manifiesto las diferencias existentes entre clima/tiempo real y percibido, enfatizando, al mismo tiempo, la utilidad de las imágenes mentales -climáticas y meteorológicas- para la planificación y gestión del territorio (Martín-Vide, 1990; Martín-Vide, 2001). Asimismo, se ha 
estudiado la percepción de los cambios climáticos a través de la historia a partir de fuentes de información muy diversas que se remontan a la Antigüedad más pretérita (Olcina et at., 1999: cap. 2; Olcina, 2009).

\subsection{La percepción del cambio climático en la década de 1990 y el papel de los me- dios de comunicación en la representación social del problema}

Se ha sugerido que las primeras informaciones sobre un cambio climático de origen antrópico, que comenzaron a filtrarse a la opinión pública internacional hacia finales de los años ochenta, se difundieron a través de noticias que mezclaban este fenómeno con el del deterioro de la capa de ozono estratosférico, lo que a la postre acabaría teniendo grandes repercusiones en la imagen social del calentamiento global (Weart, 2006: 183). La percepción social del cambio climático cuenta con algunos trabajos interesantes que suministran información sobre las actitudes y preocupaciones de la población acerca de esta problemática ambiental. Diferentes autores vienen explorando esta cuestión desde la década de 1990, valiéndose, fundamentalmente, de técnicas cualitativas como la entrevista o la encuesta. En Estados Unidos, Willet M. Kempton (1991) estudió las diferencias entre la percepción de los científicos y la de los ciudadanos no expertos, señalando que estos últimos eran incapaces de asociar el cambio climático con el desmedido consumo energético de su país. Equivocaciones de este tipo también fueron advertidas por Daniel Read et al. (1994a; 1994b), que además encontraron frecuentes confusiones entre el cambio climático y aquel otro problema ambiental al que nos acabamos de referir: el del agujero de la capa de ozono.

Por su parte, E. Boyes et al. (1993) realizaron una encuesta a estudiantes estadounidenses de entre 11 y 16 años sobre las causas, consecuencias y posibles soluciones del calentamiento global, concluyendo que durante la secundaria se erradicaban muchos de los errores detectados entre los alumnos más jóvenes. Ello, sin embargo, no obstaba para que los estudiantes de los cursos superiores conservaran algunas equivocaciones flagrantes, como la de que el uso de carburantes sin plomo contribuye a mitigar el efecto invernadero. Según los autores, el principal error en la percepción de los niños residía en que éstos eran incapaces de relacionar las causas del cambio climático con sus consecuencias, y tampoco podían discernir entre las acciones que permiten combatir el calentamiento global y las que sirven para hacer frente a otros problemas ambientales. Por tanto, se hacía necesario dirigir la educación de los alumnos hacia una mejor conceptualización del cambio climático, idea que Kempton (1993) desarrolló con mayor profundidad, reconociendo, al mismo tiempo, que se estaban produciendo avances notables al respecto. 
Irene Lorenzoni et al. (2006: 76) han mostrado cómo ha evolucionado la preocupación social por el cambio climático en Europa. Desde fines de los años ochenta se vienen publicando demoscopias que incluyen preguntas sobre la inquietud de la población respecto a problemas ambientales como el cambio climático. Aunque los datos no son comparables debido a que las preguntas fueron formuladas de forma distinta en las sucesivas ediciones de los sondeos, al menos muestran las tendencias básicas de la opinión pública europea acerca del cambio climático. En 1988, un nada desdeñable 76 por ciento de los encuestados en la UE-12 se mostraba muy o algo preocupado por el efecto invernadero. Cuatro años después, la inquietud social por el cambio climático había crecido, pues un 62 por ciento de los europeos se declaraba «muy preocupado» y un 27 por ciento «algo preocupado». Sin embargo, en 2002 la preocupación había declinado en la UE-15, pues sólo un 39 por ciento de los encuestados se sentía «muy preocupado». Además, los niveles de inquietud más elevados se registraban en países mediterráneos -Italia y Grecia-, una pauta que, como tendremos ocasión de comentar, todavía persiste en la actualidad.

Pese a no ser muy numerosos, se han publicado algunos estudios que comparan las visiones sociales del cambio climático en distintos países. En el ámbito europeo puede citarse el trabajo de J. Burgess et al. (1998), que analiza la percepción ambiental en el sector privado, el sector público y el «tercer sector social» de dos ciudades: Nottingham (Reino Unido) y Eindhoven (Países Bajos). Riley E. Dunlap (1998) describió, a partir de una encuesta realizada en 1992, la percepción del cambio climático en Canadá, Estados Unidos, México, Brasil, Portugal y Rusia, siendo los encuestados de este último país los que mostraban un menor nivel de concienciación del problema. De todos modos, en el resto de países la mayor parte de los encuestados opinaba que el cambio climático era menos grave que otras problemáticas ambientales, como la del agujero de la capa de ozono o la desaparición de las selvas tropicales. Por su parte, Richard J. Bord et al. (1998) encontraron muchas similitudes en las actitudes sociales ante el cambio climático. Aunque éste parecía suscitar mayor interés entre la población canadiense, europea y sudamericana, los autores señalaron que, globalmente, existía una conciencia generalizada de la existencia del cambio climático; un conocimiento defectuoso de los mecanismos físico-químicos que lo desencadenan; una conceptualización del mismo en tanto que amenaza, aunque menos grave que la que podían representar otros problemas ambientales; y una predisposición muy limitada a cambiar de estilo de vida para mitigar el calentamiento global.

En España, Ana M ${ }^{a}$ Camarasa et al. (1994) dieron a conocer un trabajo en el que se destacaba que la muestra de población estudiada daba por sentada la existencia de un cambio climático de origen antrópico y con capacidad para provocar 
grandes eventos catastróficos. Los autores señalaron, a modo de conclusión, que se trataba de una imagen distorsionada por los medios de comunicación, pues la investigación científica no había podido demostrar unívocamente que el planeta se estaba calentando como consecuencia de la acción humana. Ciertamente, en 1994 la comunidad científica todavía mostraba una gran indeterminación ante el fenómeno del cambio climático, por lo que la conclusión del artículo parece razonable e, incluso, acertada. Sin embargo, este caso -anecdótico- deja traslucir la necesidad de no renunciar a ninguna fuente de conocimiento cuando las incertidumbres son grandes.

En general, se advierte que en la década de los noventa la población era consciente de que el sistema climático mundial estaba experimentando alteraciones importantes y que ello podía representar una amenaza para la sociedad, aunque de menor calibre que la que suponía la disminución del ozono estratosférico. Sin embargo, las causas y consecuencias del calentamiento planetario eran comprendidas de un modo defectuoso, y no siempre se sabía discernir el cambio climático de otros problemas ambientales, con lo cual se tendía a creer que cualquier acción servía para mitigarlo por más que fuera «amigable» con el medio ambiente. Nuestra hipótesis es que en la actualidad, el conocimiento sobre el cambio climático que posee la ciudadanía ha dado un salto cuantitativo y cualitativo extraordinario, y en ello ha tenido mucho que ver la difusión de noticias sobre el calentamiento global en los medios de comunicación.

Como los temas demográficos, que a fin de cuentas se reducen al sexo y la muerte, el cambio climático congrega una serie de elementos que lo hacen sumamente atractivo para los mass media, que casi a diario difunden noticias sobre esta problemática ambiental. Al decir de Javier Martín-Vide (2008: s/p.), «el cambio climático reúne al menos seis condiciones para su consideración como tema 'estrella' en los medios de comunicación: 1) es nuevo, o 'novedoso'; 2) no es efímero; 3) es medioambiental; 4) tiene morbo; 5) puede formularse sencillamente y, a la vez, 6) es complejo». Una sencilla búsqueda en la hemeroteca digital de La Vanguardia (2009) del número de ocasiones que la expresión «cambio climático» ha aparecido en las páginas de este rotativo barcelonés, pone al descubierto la importancia progresiva y creciente que el asunto ha ido adquiriendo en los últimos años. En las dos décadas transcurridas entre 1990 y 2009, el término se ha repetido un total de 2.688 veces, repartidas quinquenalmente del siguiente modo: 217 en 1990-1994 (8,07 \%), 326 en 1995-1999 (12,13 \%), 538 en 2000$2004(20,01 \%)$ y 1.607 en 2005-2009 (59,78\%) (resultados obtenidos el 21 de mayo de 2009). Por tanto, a medida que transcurrían los años, el término ha sido de uso cada vez más frecuente, lo que trasluce una preocupación creciente por el asunto. Resultados muy parecidos ofrecen las distribuciones quinquenales 
de otras dos expresiones relacionadas con el cambio climático, como son las de «efecto invernadero»y «calentamiento global».

Aunque a veces las noticias difundidas por los medios de comunicación son deficientes o directamente erróneas, qué duda cabe que la amplia cobertura mediática que ha merecido el cambio climático ha contribuido a popularizar este problema ambiental. Otra cosa son los efectos producidos en la opinión pública por el «bombardeo» diario de informaciones y noticias. Un estudio ha puesto de manifiesto que, a diferencia de otros países, en Estados Unidos los medios de comunicación tienden a minusvalorar la gravedad del calentamiento global, lo que se ha relacionado con la existencia de fuertes vínculos financieros entre algunos media y determinadas industrias contaminantes (Dispensa et al., 2003). Sin embargo, también se ha subrayado el papel de Time Magazine en la formación de un estado de opinión sobre cuestiones como los «refugiados ambientales» o la decisión del gobierno estadounidense de rechazar el Protocolo de Kioto (Feldmann et al., 2001: 288). Asimismo, se han estudiado las consecuencias en la opinión pública mexicana del tratamiento informativo realizado por el diario Reforma, que tiende a privilegiar los aspectos científicos del cambio climático (Deines, 2005). En Gran Bretaña, se ha demostrado que existe cierta correlación entre la percepción del cambio climático y la presencia de este tema en los medios de comunicación (Lacey et al., 1997). Incluso se han analizado las viñetas humorísticas sobre el cambio climático publicadas en Cataluña, por constituir, hipotéticamente, «un medio muy válido y significativo a la hora de interpretar de forma integral las percepciones sobre procesos complejos» (Tàbara, 2005: 807).

Con todo, según Allan Bell (1994: 38), que estudió la percepción del cambio climático en la sociedad neozelandesa, la población no asume pasivamente la información mediática, sino que interpreta los contenidos de las noticias desde la perspectiva de sus propios puntos de vista, aceptando aquellas informaciones que refuerzan las actitudes preexistentes. Por tanto, la información mediática sólo aumenta el conocimiento de la audiencia cuando ésta posee un entendimiento previo de la cuestión, de modo que los medios de comunicación no tienen por qué constituir la única fuente de conocimiento, sino una más -aunque importante- de las que dispone el ciudadano para formarse una idea de las actuales alteraciones climáticas del planeta.

En este sentido, puede señalarse que en escuelas y universidades se imparten desde hace años enseñanzas rigurosas sobre los procesos físico-químicos que desencadenan el cambio climático y sus consecuencias ecológicas, económicas y sociales. Asimismo, con frecuencia, científicos de reconocido prestigio pronuncian conferencias públicas que versan sobre esta materia y a las que puede asistir 
un público general. A ello hay que añadir la ingente cantidad de información disponible en Internet de forma gratuita. En el motor de búsqueda Google la expresión «cambio climático»-entrecomillada- obtiene más de cinco millones de resultados, cifra semejante a la lograda por «globalización» y muy superior a la alcanzada por «sostenibilidad», que constituyen otros dos términos que han hecho fortuna (resultados obtenidos el 21 de mayo de 2009). Bien es cierto que una parte de la información publicada en línea presenta graves deficiencias, pero también lo es que el ciudadano puede acceder a documentación digital que combina la precisión científica con el rigor pedagógico. Finalmente, no puede soslayarse la influencia del documental Una verdad incómoda (An inconvenient truth, 2006), dirigido por Davis Guggenheim y conducido por el político estadounidense Al Gore. Son muchos los defectos que pueden achacarse a esta producción cinematográfica -derivaciones políticas, personalismos, contradicciones, etc.-, pero no se le puede negar su influencia en la difusión planetaria de la existencia del cambio climático (Escudero, 2008: s/p.).

La atención creciente dispensada a esta problemática ambiental por los medios de comunicación, combinada con el efecto de otras fuentes de información, puede explicar la mejora del conocimiento y concienciación de la ciudadanía sobre el cambio climático, que a tenor de las publicaciones más recientes pueden calificarse de óptimos.

De todos modos, conviene dejar anotada la dificultad que reviste abordar esta cuestión. En primer lugar, porque, desde una perspectiva general, la construcción de la cultura popular es un proceso sumamente complejo. Aunque parezca evidente que ésta es una creación del «pueblo» que finalmente resulta reconocida por las élites cultas, algunos autores han mostrado que también puede constituir una creación culta que posteriormente se vulgariza y difunde «hacia abajo», lo que por ejemplo se ha subrayado en relación a las creencias sobre la estructura física de la Tierra (Capel, 1980: 73). Por otro lado, debe señalarse que en la formación social del objeto «cambio climático» inciden diversas variables de orden psicológico y sociocultural que no siempre son bien comprendidas o valoradas (Leiserowitz, 2006: 46). Algunos estudios ofrecen resultados que, a priori, resultan sorprendentes. Así, por ejemplo, se ha mostrado que el grado de preocupación de los estadounidenses por el cambio climático no es creciente, sino fluctuante a lo largo del tiempo, alcanzando en 1989 cotas superiores a las de 2003 (Brenchin, 2003: 111-112). Aunque este comportamiento podría explicarse en razón de la alta maleabilidad de la opinión pública, que tiende a ser muy mediatizada por las circunstancias contextuales, faltan estudios sistemáticos que expliquen el conjunto de elementos que inciden en la representación social del cambio climático. 
Con todo, como se tratará de mostrar a continuación, pueden identificarse algunas pautas generales relativas a cuatro dimensiones básicas: la identificación del cambio climático como problema; la concienciación sobre su potencial de amenaza; la idoneidad y ajuste científico de los conocimientos que atesora la población; y su predisposición a adoptar medidas para la atenuación del problema. Veamos qué percepción tienen al respecto las sociedades europea, española y catalana.

\subsection{La percepción actual del cambio climático en la Unión Europea, España y Ca- taluña}

\subsubsection{El cambio climático en la sociedad europea}

Aunque no tenemos noticia de la existencia de demoscopias específicas sobre las actitudes de los europeos acerca del cambio climático, pueden extraerse conclusiones interesantes de un reciente sondeo sobre la percepción ambiental en general elaborado a partir de 27.000 entrevistas realizadas en todos los países de la Unión (European Commission, 2008). Los resultados no ofrecen dudas sobre la concienciación social del calentamiento global, ya que un 19 por ciento de los encuestados manifiesta que la primera idea que asocia con el término «medio ambiente» es la de «cambio climático», respuesta sólo superada por la genérica «contaminación urbana» (22\%). De todos los problemas ambientales, el cambio climático es percibido como la principal amenaza ( $57 \%$ ), a quince puntos de distancia de la segunda, que es la contaminación hídrica. Respecto al año 2004, la conceptualización del cambio climático como problema ha aumentado en doce puntos y, actualmente, es mencionado como la problemática ambiental más apremiante en veintiún de los veintisiete estados miembros, especialmente en Chipre (79 \%) y Suecia (71 \%). Pese a la complejidad del asunto, sólo un 26 por ciento de los encuestados reconoce que carece de información al respecto, existiendo otros cuatro problemas ambientales donde las lagunas informativas son mayores: el impacto de los productos químicos en la salud (36\%), el uso de organismos genéticamente modificados (34\%), la contaminación química de los productos alimentarios (28\%) y la contaminación del agua ( $27 \%$ ).

El estudio también ofrece datos sobre las actitudes de los europeos hacia la protección del medio ambiente. La gran mayoría de los encuestados (86 \%) opina que a título individual se puede contribuir a este objetivo y, en promedio, cada uno de ellos realiza 2,6 acciones mensuales para preservar el entorno. De entre ellas, la más mencionada es la separación y reciclaje de los residuos domésticos (59 \%), una práctica que se halla bien instituida en diversos países europeos, mientras que el 47 por ciento de los encuestados afirma que durante el último mes ha reducido su consumo energético por razones medioambienta- 
les, medida que contribuye a la mitigación del cambio climático. Otras acciones de este tipo llevadas a cabo por los encuestados son la utilización de medios de transporte alternativos al vehículo privado $(28 \%$ ) y la reducción del uso del automóvil (17\%). Aunque el estudio no indaga en los motivos concretos que llevan a realizar estas acciones, es de suponer, a la vista del elevado nivel de concienciación social del cambio climático, que la atenuación del mismo constituye una razón de peso.

Como complemento de la cuestión anterior, se preguntó acerca de las acciones que la ciudadanía debería priorizar de cara a proteger el medio ambiente. El reciclaje (55\%) y la disminución del consumo energético (47\%) son, de nuevo, las dos respuestas más repetidas, por lo que los europeos tienden a esperar que sus conciudadanos realicen las mismas acciones que ellos mismos desarrollan en su vida cotidiana. Se advierten, no obstante, algunas diferencias significativas entre los «viejos» y «nuevos» países de la Unión Europea, ya que mientras aquéllos tienden a priorizar la reducción del consumo energético, éstos son más proclives a la compra de productos etiquetados como «ecológicos».

Otro aspecto interesante es el relativo a la opinión de los europeos acerca de las políticas públicas de defensa del medio ambiente y su incidencia en la economía. Un 63 por ciento de los encuestados opina que esas políticas no sólo no constituyen un obstáculo para el desarrollo económico, sino que representan un incentivo para la innovación; un 64 por ciento cree que la protección ambiental debe prevalecer sobre las consideraciones relativas a la competitividad económica; y un 67 por ciento considera que la medición del progreso tendría que atender a criterios sociales y ecológicos además de económicos. A menudo, los gobiernos, de forma más o menos encubierta, han eludido adoptar medidas para combatir el cambio climático esgrimiendo que representan cortapisas para el desarrollo económico. Sin embargo, a la vista de los resultados, este razonamiento no ha calado en la sociedad europea, que parece adscribirse a posturas mucho más progresistas y sensatas. En este sentido, debe señalarse que los políticos inspiran un muy bajo nivel de confianza cuando abordan cuestiones ambientales, ya que sólo un 9 por ciento de los encuestados afirma dar preferencia a las opiniones de sus gobiernos nacionales respectivos. Por el contrario, las asociaciones ecologistas, la comunidad científica y algunos medios de comunicación gozan de mucho más crédito entre la opinión pública.

Por otro lado, existen notables diferencias generacionales a la hora de mostrar predisposición a adoptar medidas de respuesta al cambio climático que acarreen un coste económico individual. En efecto, los europeos de 15 a 24 años tienden a reconocer que la atenuación del calentamiento global exige la asunción de costes personales, mientras que entre los mayores de 65 años el consenso 
respecto a esta cuestión no es ni mucho menos mayoritario. Aunque esta diferencia podría deberse a la distinta información ambiental manejada por unos y otros, Joni Hersh et al. (2006: 134) sostienen que el mayor apoyo de los jóvenes se explica por el hecho de que perciben que saldrán personalmente beneficiados de las políticas contra el cambio climático, mientras que la población anciana no siente que éstas les acarreen un beneficio personal directo.

En otro sondeo sobre las actitudes de la población relativas a la política energética de la Unión Europea (The Gallup Organisation, 2007), un 50 por ciento de los encuestados declara sentirse «muy preocupado» por el cambio climático, mientras que un 37 por ciento dice que el tema le inquieta en algún modo. Pero mayor interés reviste la distribución geográfica de las respuestas, ya que es en los países de Europa meridional donde los ciudadanos muestran un mayor nivel de preocupación. En efecto, una mayoría de los encuestados en España (70 \%), Chipre (70 \%), Malta (68 \%), Grecia (68 \%), Portugal (65\%), Rumanía (64\%) e Italia (58 \%) se posiciona como muy preocupada ante el cambio climático. De estos siete países cinco pertenecen a la cuenca mediterránea, por lo que la mayor inquietud social puede denotar cierto temor a la gran vulnerabilidad de este entorno, que por ejemplo se ha puesto de manifiesto en relación a los procesos erosivos del suelo (Boix et al., 1999). Asimismo, los países en los que se detecta una mayor sensibilidad por las consecuencias ambientales del consumo de energía pertenecen a la región mediterránea: España, Italia y Grecia, donde, respectivamente, un 63, 48 y 45 por ciento de los encuestados señala que el gasto energético implica graves impactos ambientales.

La caracterización de la percepción social del cambio climático en Europa puede complementarse con algunos de los resultados globales del proyecto ULYSSES (Urban Lifestyles, Sustainability and Integrated Environmental Assessment). Este proyecto de investigación, realizado durante los años 1996-1999, persiguió el objetivo de desarrollar metodologías de participación ciudadana en la definición de las políticas ambientales, para lo cual se organizaron grupos de discusión y evaluación integrada en siete ciudades europeas: Atenas, Barcelona, Estocolmo, Frankfurt, Mánchester, Venecia y Zúrich. Este tipo de experiencias posee un valor extraordinario de cara a llenar el vacío actualmente existente entre el contenido de las políticas ambientales y las visiones de los ciudadanos (van der Sluijs, 2002: 460). Las personas que participaron en las sesiones del proyecto ULYSSES tendieron a mostrar una gran preocupación por los impactos futuros del cambio climático. Previendo un deterioro generalizado de las condiciones de vida, especialmente de las de las generaciones futuras, ubicaron el debate en el plano ético y no tanto económico, y juzgaron como inaceptable el que los gobiernos permanezcan impasibles ante esta problemática ambiental (Kasemir, 2001: 131). 
En cuanto a las propuestas de mitigación, la mayoría de los ciudadanos puso el acento en la cuestión energética, opinando que debería reducirse de forma sustancial el consumo de energía mediante la mejora de la eficiencia energética de los productos (Kasemir, 2001: 131; v. et. Kasemir et al., s/f.).

A tenor de todo lo expuesto, puede concluirse que la población europea posee un muy elevado nivel de concienciación del cambio climático, al que percibe como la principal amenaza ambiental de nuestros tiempos. El grado de preocupación es mayor entre los ciudadanos de los países ribereños del Mediterráneo, que se cuentan entre los más vulnerables del mundo a las alteraciones del sistema climático. Asimismo, la sociedad europea atesora un conocimiento razonablemente adecuado de la materia, lo que le permite identificar el desmedido consumo energético como principal causante del calentamiento global. Por otro lado, la ciudadanía europea tiende a aproximarse al fenómeno atendiendo a una pluralidad de criterios, incluyendo creencias y valores personales, y antepone el combate del cambio climático al fomento del crecimiento económico.

\subsubsection{El cambio climático en la sociedad española}

A diferencia de otros países del entorno europeo, España no cuenta con una tradición de estudios demoscópicos sobre la representación social del cambio climático. Afortunadamente, en los últimos años han visto la luz dos publicaciones (Fundación BBVA, 2008 y Meira et al., 2009) que, unidas a los datos del Centro de Investigaciones Sociológicas (CIS) y al trabajo de síntesis de Pablo Ángel Meira y Mónica Arto (2008), permiten aprehender los rasgos esenciales de la percepción del cambio climático en nuestro país.

El cambio climático comenzó a trascender al conjunto de la sociedad española hacia mediados de los años noventa y, desde entonces, ha ido adquiriendo una relevancia creciente, de modo que en la actualidad un 90,7 por ciento de la población ha oído hablar del fenómeno, lo que supone cerca de doce puntos más que en 2005 (Fundación BBVA, 2008: 8). Además, un 85,1 por ciento de los ciudadanos cree que el planeta está experimentando un cambio climático, cuyos efectos más notorios son un aumento de la temperatura $(34,4 \%)$ y una reducción de la precipitación (21,1\%), y solamente un 4,6 por ciento de los españoles mantiene una actitud negacionista (Fundación BBVA, 2008: 11). Estos datos concuerdan con los del CIS (2007: s/p.), según los cuales un 82,9 por ciento de los entrevistados opina que estamos asistiendo a un proceso de calentamiento global. En consecuencia, prácticamente toda la población española tiene noticias de la existencia del cambio climático y afirma que éste se está produciendo, lo cual es muy significativo, porque difícilmente puede hacerse frente a un problema si la sociedad lo ignora (Meira y Arto, 2008: 36). 
Cabe advertir que más de ocho de cada diez españoles afirman haber notado un aumento de la temperatura media en su región de origen a lo largo de las dos últimas décadas (Fundación BBVA, 2008: 10), cosa poco probable, dado que la capacidad sensorial del ser humano no le permite captar alteraciones térmicas que se miden en décimas de grado centígrado. Posiblemente, el propio convencimiento de que el planeta se está calentando, unido a la intensificación del fenómeno de la «isla de calor» en los entornos urbanos, expliquen la percepción tan generalizada de que la temperatura media viene aumentando desde hace veinte años. Por lo demás, ello deja traslucir la necesidad de adoptar ciertas cautelas ante este tipo de opiniones «sensitivas» vertidas por el ciudadano en relación al clima.

En lo que a la conceptualización del cambio climático se refiere, los datos resultan algo ambiguos. Por un lado, un 14,3 por ciento de los españoles menciona el calentamiento global como una de las dos problemáticas más apremiantes del mundo, superada, únicamente, por los problemas económicos (40,6 \%), los conflictos bélicos (32,7\%), el hambre (31,5\%) y los problemas ambientales en general (25,6 \%). Pero por otro lado, sólo un 3,7 por ciento de los ciudadanos considera que el cambio climático constituye uno de los problemas que más afectan a España, a mucha distancia del desempleo (36,9 \%), la pobreza $(36,0$ \%), el terrorismo (27,3\%) y otros fenómenos (Meira et al., 2009: 18 y 20). Por lo tanto, mientras que el cambio climático tiende a ser identificado como una de las mayores amenazas planetarias, y la más grave de las de índole ambiental, pierde relevancia cuando los referentes espaciales son más cercanos, lo que denota la dificultad de percibir sus impactos en el día a día. Es por ello que se ha señalado que «uno de los retos de las políticas de lucha contra el cambio climático es, sin duda, acercar esta problemática a los entornos vitales más cercanos y significativos para las personas» (Meira et al., 2009: 24-25). De todos modos, parece que la capacidad de preocupación del individuo es limitada, por lo que un aumento de la inquietud social por el cambio climático podría derivar en una relajación del interés por otros temas (Weber, 2006: 114). Ello debe tenerse en cuenta a la hora de evocar las consecuencias del cambio climático, ya que existen otros muchos problemas sobre los que no conviene bajar la guardia.

Los estudios demoscópicos del CIS (2007, s/p.), de la Fundación BBVA (2008: 14) y de la Fundación Mapfre (Meira et al., 2009: 51) coinciden en señalar que la población española siente que el cambio climático no está recibiendo la atención que se merece. Pero, paralelamente, los ciudadanos tienden a diferir en el tiempo los impactos del calentamiento global, ya que un 67,3 por ciento estima que éste sólo representará un problema «muy importante» para las generaciones venideras (Fundación BBVA, 2008: 15). Aunque los resultados no 
permiten ni mucho menos afirmar que exista un distanciamiento social de la problemática, se advierte cierta tendencia a aplazar su amenaza, pauta que viene a sumarse a la de deslocalizar sus impactos. En consecuencia, científicos y políticos deberán redoblar esfuerzos para convencer a la ciudadanía de que el cambio climático no es un problema virtual, sino que sus efectos son potencialmente peligrosos para la sociedad española actual. En otras palabras, deberán transmitir un mensaje inequívoco al respecto: «el cambio climático ya está aquí y ha venido para quedarse». De lo contrario, los ciudadanos dispondrían de una justificación para retrasar su disposición a cambiar de hábitos de comportamiento en aspectos relevantes desde la perspectiva de la mitigación del problema.

La adopción de respuestas adecuadas para hacer frente al cambio climático también dependerá, en gran medida, de la comprensión social del fenómeno. El que éste sea asumido por prácticamente toda la sociedad española no implica, ni mucho menos, que los conocimientos manejados por la ciudadanía se ajusten a la realidad científica. Al respecto, cabe señalar que no ha podido erradicarse aquella vinculación tan común en los años noventa entre el cambio climático y el deterioro de la capa de ozono, problema que está en vías de solución y que ha perdido gran parte de la cuota mediática que mereció en la última década del siglo XX. El error no reside tanto en una confusión de ambas problemáticas, como en una identificación equivocada de la causa que provoca el calentamiento del planeta, dado que un 71,2 por ciento de los encuestados cree que éste está motivado por la existencia de un agujero en la capa de ozono (Fundación BBVA, 2008: 9).

En cierto modo, la metáfora del «agujero» ofrece una explicación sencilla, coherente y de «sentido común», a un problema de gran complejidad científica como es el calentamiento global. En efecto, al ciudadano de a pie, que no está familiarizado con los procesos físicos y químicos que tienen lugar en la atmósfera, le resulta mucho más esquemático y racional pensar que como consecuencia de la existencia de un agujero en el cielo la radiación solar penetra con mayor facilidad en la Tierra, con lo cual ésta tiende a calentarse. De ahí que, en adelante, la comunidad científica deba atender a los procesos de simplificación cognitiva a la hora de difundir socialmente determinados mensajes, pues una vez establecido el malentendido, resulta sumamente difícil erradicarlo. Por el mismo motivo, no puede dejar de criticarse la popularización de otra imagen simplificadora pero que explica de forma deficiente las relaciones causa-efecto del cambio climático. Nos referimos a la imagen del «efecto invernadero», que está bien lejos de revelar los procesos físico-químicos que desencadenan el calentamiento del planeta.

Con todo, el tema de la construcción social del cambio climático es mucho más complejo de lo que pueda parecer, dado que a la relación de causalidad 
errónea establecida entre la reducción del ozono estratosférico y el calentamiento del planeta, se suma una percepción generalizada, esta vez acertada, de que las emisiones de GEI constituyen la principal causa del aumento de la temperatura mundial. Esta visión, compartida por un 73,6 por ciento de los ciudadanos encuestados por la Fundación BBVA (2008: 9), se complementa con la opinión bastante arraigada de que el cambio climático es un problema de origen antrópico $(64,8 \%)$ motivado, en primer lugar, por las emisiones de $\mathrm{CO}_{2}(34,6 \%)$, elevándose al 63,0 el porcentaje de población que identifica este gas como uno de los tres principales causantes del calentamiento global (Fundación BBVA, 2008: 19-20). No hace falta insistir en la importancia que adquieren estos resultados de cara a la adopción de medidas paliativas, dado que parece obvio que un buen entendimiento de la responsabilidad humana en la génesis del problema constituye una condición indispensable para que la sociedad se avenga a modificar sus hábitos de vida.

Por otro lado, la población española tiende a concretar esa responsabilidad en la esfera de la cotidianeidad. Dos de cada tres personas encuestadas por la Fundación Mapfre coinciden en señalar que las acciones individuales sí pueden influir en el cambio climático, aunque, al mismo tiempo, la mayoría de los encuestados (88,9\%) imputa el mayor grado de responsabilidad a las grandes industrias (Meira et al., 2009: 57 y 65). Los comportamientos de la vida diaria a los que se atribuye una mayor incidencia son el uso del automóvil $(7,4$ en una escala del 0 al 10), la compra de electrodomésticos de alto consumo $(7,2)$, el viajar en avión $(7,0)$ y la calefacción del hogar $(7,0)$ (Fundación BBVA, 2008: 21). Todos ellos son hábitos ligados al consumo de energía, que, efectivamente, es el principal responsable de la emisión de GEI antropogénicos. No obstante, otros causantes, como las actividades agrícolas y ganaderas, son menos conocidos entre los ciudadanos, por lo que parece conveniente difundir socialmente información sobre sus efectos.

La población atesora un conocimiento relativamente óptimo de los efectos ecológicos que el cambio climático puede desencadenar en un horizonte de veinticinco años, pero parece minusvalorar o desconocer sus potenciales impactos sociales, políticos y económicos. Así, por ejemplo, sólo un 26,2 por ciento estima como «muy probable» que se produzca un aumento de la incidencia de determinadas enfermedades (Fundación BBVA, 2008: 24), y si atendemos a otro sondeo, resulta que la segunda consecuencia sanitarias más esperada es el aumento del riesgo de padecer cáncer de piel (Meira et al., 2009: 61). Este efecto no es contemplado por la literatura científica, y su popularidad reside, muy probablemente, en la asociación generalizada del deterioro de la capa de ozono con el calentamiento global. En cambio, la expansión de enfermedades que actual- 
mente sólo son endémicas en determinados entornos tropicales, o el aumento de la producción de pólenes alergénicos, efectos que ya han sido documentados con un grado de confianza medio (IPCC, 2007: 33), no figuran entre las preocupaciones más apremiantes de la ciudadanía española. En consecuencia, a fin de construir una percepción ciudadana más completa del cambio climático, parece necesario divulgar el mensaje de que éste puede llegar a generar unos impactos que van mucho más allá de las alteraciones ecosistémicas.

Una última dimensión que conviene abordar es la relativa a la representación social de la lucha contra el calentamiento global, aspecto sumamente trascendente, ya que de ello dependerá, en buena medida, la predisposición a actuar para afrontar el problema. Una gran mayoría de la población opina que es necesario adoptar medidas inmediatas para combatir el cambio climático $(83,5 \%)$ y que para alcanzar dicho objetivo habrá que modificar significativamente nuestro estilo de vida (88,6 \%); incluso, un 71,7 por ciento de los ciudadanos se muestra dispuesto a alterar sus hábitos de comportamiento para contribuir a mitigar el calentamiento global (Fundación BBVA, 2008: 26-27 y 31). Estos datos parecen sugerir la existencia de una demanda social de estrategias de respuesta al cambio climático que impliquen modificaciones sustanciales de los hábitos de vida. Sin embargo, cuando se interroga acerca de medidas concretas, las que generan mayor rechazo son, precisamente, aquéllas que afectan a la esfera personal. Así, sólo un 18,4 por ciento de los ciudadanos apoyaría un incremento de la tarifa eléctrica, mientras que un 64,7 por ciento de los usuarios de automóvil no vería con buenos ojos un aumento de los impuestos que gravan a los carburantes (Fundación BBVA, 2008: 32-33).

Parte de la explicación de este desajuste puede residir en la llamada sensación de «sobre-pasamiento», que se experimenta cuando se percibe que la acción individual tendrá efectos inapreciables ante la magnitud de un problema mundial, o cuando se interpreta que dicha acción será anulada por el comportamiento «irresponsable» de otros (Meira y Arto, 2008: 43). De ahí que sea necesario potenciar aquellos mensajes que incidan en el carácter socialmente compartido que posee la lucha contra el cambio climático y que, al mismo tiempo, muestren el efecto agregado que suponen las acciones individuales.

En cuanto a la percepción de las políticas públicas para hacer frente al cambio climático, la gran mayoría de la población española $(80,6$ \%) apuesta por la concertación de medidas internacionales, aunque las opiniones están divididas sobre si los acuerdos deben fijar idénticos plazos y exigencias para todos los países del mundo (Fundación BBVA, 2008: 32-33). Pese a que un 40,0 por ciento de los encuestados opina que deberían adoptarse todas las medidas necesarias, todavía un 39,6 por ciento matiza que convendría descartar aquéllas que supon- 
gan un mayor obstáculo para el crecimiento económico (Fundación BBVA, 2008: 36). Las estrategias de mitigación que obtienen un mayor respaldo social son el establecimiento de límites más estrictos sobre la cantidad de contaminación permitida a las industrias $(62,8 \%)$, la prohibición de los productos que generen mayor contaminación, siempre y cuando existan alternativas (30,5\%), y el fomento de los medios de transporte que no sean el vehículo privado (28,2 \%) (CIS, 2007: s/p.). Asimismo, una gran mayoría de la población española $(74,3 \%)$ no cree que la energía nuclear constituya una solución válida al problema, debido a los riesgos asociados a su producción, opinión que también se ha detectado en otros estudios realizados en países de nuestro entorno (v. e.g. Poortinga, 2006: 8).

Aunque esta somera caracterización de la visión social del cambio climático en España podría enriquecerse considerando otras dimensiones o desagregando los datos en función del lugar de residencia, el sexo, la edad o el nivel de instrucción, cuanto menos permite identificar los rasgos esenciales de la representación del fenómeno en nuestro país. La sociedad española acredita un muy elevado nivel de concienciación de la amenaza que representa el cambio climático y, pese a la persistencia de algunas equivocaciones o imprecisiones, atesora un conocimiento adecuado de la materia, que le permite identificar cuáles son las principales causas del problema y qué medidas contribuyen a atenuarlo. No obstante, ello no se traduce en una predisposición clara y unívoca a asumir el esfuerzo que representa hacer frente a esta amenaza y sólo parece existir consenso acerca de las medidas cuyo coste se repartiría entre toda la colectividad. Políticos y científicos deberán trabajar conjuntamente para modificar este escenario atinando el contenido de los mensajes que decidan difundir. Asimismo, puede plantearse, a modo de hipótesis, que otra forma de movilizar la acción individual es haciendo directamente partícipe al ciudadano de los procesos de decisión que afectan al cambio climático, es decir, buscar su complicidad otorgándole mayores cuotas de protagonismo en la investigación y gestión de la problemática.

\subsubsection{El cambio climático en la sociedad catalana y barcelonesa}

Como colofón de este apartado e introducción del siguiente, se van a señalar los trazos fundamentales de la percepción del cambio climático en la sociedad catalana, haciendo especial hincapié en la visión que poseen los barceloneses. Aunque escasean los estudios sobre la representación social de este fenómeno en Cataluña, hemos podido consultar tres trabajos de Joan David Tàbara (2000; 2003; 2005), más un cuarto coordinado por este mismo autor (Tàbara, 2008), en los que se aborda la cuestión de forma más o menos directa. 
En un sondeo de opinión realizado en 1994 sobre una lista cerrada de problemas ambientales con incidencia planetaria, la gravedad del cambio climático fue valorada con 7,12 puntos sobre una escala de 9, apareciendo en un discreto sexto lugar, por detrás de la destrucción de las selvas tropicales $(7,74)$, el vertido y exportación de residuos $(7,45)$, los riesgos nucleares $(7,42)$, el deterioro de la capa de ozono $(7,34)$ y la pérdida de biodiversidad $(7,32)$. Además, el número de respuestas «no sabe/no contesta» que obtuvo el cambio climático sólo fue superado por el que cosecharon los riesgos asociados a la biotecnología, de lo que puede inferirse que el calentamiento global figuraba entre las problemáticas ambientales más desconocidas por la población catalana. En 2000, el cambio climático sólo era mencionado como la principal amenaza ambiental por un 7 por ciento de los encuestados, mientras que el agujero de la capa de ozono era considerado como tal por un 37,9 por ciento. Con todo, el nivel de preocupación social que suscitaba el calentamiento global había aumentado respecto a los niveles de 1994, pues en 2000 el cambio climático ya era considerado por los catalanes como la tercera amenaza ambiental del planeta (sondeos citados en Tàbara, 2005: 780-781). En consecuencia, la preocupación ciudadana por el cambio climático presentó un comportamiento bastante estable durante la segunda parte de los años noventa, aunque con cierta predisposición a aumentar.

Las demoscopias más recientes evidencian una modificación de la tendencia, pues un 24 por ciento de los ciudadanos del principado opina que el cambio climático constituye la mayor amenaza planetaria de carácter ambiental, seguida, a poca distancia, por la destrucción de la capa de ozono (21 \%) y la contaminación hídrica (19 \%). Además, un 77 por ciento de la población señala que el cambio climático representa un problema suficientemente grave como para iniciar acciones de respuesta de forma más o menos inmediata, y sólo un 3 por ciento cree que la preocupación al respecto carece de justificación (Tàbara, 2008: 20). Por tanto, la sociedad catalana muestra un grado de inquietud elevado ante el calentamiento global y similar al detectado en Europa y España.

Por otro lado, la población catalana parece identificar el $\mathrm{CO}_{2}$ como uno de los agentes responsables del efecto invernadero, así como reconocer cuáles son las mayores fuentes de emisión de este gas. Así, con porcentajes de respuestas que oscilan entre el 99 y el 82 por ciento, los encuestados afirman que los automóviles, las fábricas, las plantas de combustión de carbón y la calefacción doméstica generan un aumento del $\mathrm{CO}_{2}$ atmosférico. Asimismo, una gran mayoría (92 \%) acierta al señalar que las masas arbóreas contribuyen a reducir las concentraciones de $\mathrm{CO}_{2}$, pero todavía un 75 por ciento cree, erróneamente, que las centrales nucleares emiten este GEI (Tàbara, 2008: 21-22). También se ha preguntado sobre el grado de conocimiento de diversas tecnologías propuestas para mitigar el cambio climático. En general, se advierte un nivel de conocimien- 
to elevado de las mismas, especialmente respecto a las alternativas energéticas de carácter limpio y renovable, pero aún nueve de cada diez catalanes no han oído hablar de la posibilidad de capturar y almacenar el $\mathrm{CO}_{2}$ (Tàbara, 2008: 21-22).

Los catalanes no parecen mostrar una gran predisposición a asumir el coste de la lucha contra el cambio climático, pauta que ya hemos observado en el conjunto de la sociedad española. Ciertamente, un 71 por ciento afirma estar dispuesto a pagar 5 euros más en la factura eléctrica para contribuir a mitigar el calentamiento global, pero este porcentaje desciende abruptamente a medida que aumenta la cantidad monetaria: 10 euros (50\%), 25 euros (18\%), 50 euros (5 \%) y 100 euros (2 \%) (Tàbara, 2008: 23). En cambio, las soluciones cuyo coste se repartiría colectivamente parecen suscitar un mayor nivel de aceptación. Al respecto, la población catalana muestra predilección por la sustitución de las fuentes de energía fósil, opción mencionada como prioritaria por un 42 por ciento de los encuestados. El ahorro energético figura en segundo lugar con un 16 por ciento de las respuestas, y llama la atención la gran omisión del fomento del transporte público (9\%), lo que puede denotar cierta laguna informativa al respecto (Tàbara, 2008: 25).

Por último, conviene decir algo acerca de la percepción social del cambio climático en Barcelona, para lo cual podemos utilizar algunos de los resultados de las sesiones de debate que se realizaron en esta ciudad en el marco del proyecto ULYSSES. Aunque éste se desarrolló en los años 1996-1999, su naturaleza cualitativa permite obtener una visión más matizada de las opiniones ciudadanas acerca del calentamiento global, que servirá para contextualizar la iniciativa que comentaremos en el siguiente apartado.

El análisis de las discusiones mantenidas entre los ciudadanos participantes ha permitido identificar algunas argumentaciones y actitudes significativas que, si bien no pueden ser catalogadas como representativas de la percepción general del cambio climático en la población de Barcelona, cuanto menos ilustran algunas de las ideas-base que suelen aparecer en conversaciones sobre este asunto (Tàbara, 2000: 65-70; Tàbara, 2003: 193-195; Tàbara, 2005: 782-805). En general, los participantes aceptaron la existencia del cambio climático y se mostraron partidarios de adoptar respuestas para hacerle frente, aunque, al mismo tiempo, realizaron algunas críticas a los modelos predictivos generados por ordenador, esgrimiendo que la evolución futura del calentamiento global dependerá, en última instancia, de la voluntad colectiva e individual para adoptar medidas. A menudo, los debates se situaron en el plano moral, psicológico y social, lo que, por ejemplo, llevó a concluir que muchas de las acciones que podrían implantarse para atenuar el cambio climático no se llevaban a cabo por motivos vinculados a «la comodidad», «la economía»y «los políticos». 
También es interesante constatar los cambios que se produjeron en la percepción de los individuos a medida que avanzaba el proceso. Ante todo, debe señalarse que gracias a los debates se desarrolló una especie de aprendizaje colectivo, relativo tanto al reconocimiento de las incertidumbres que genera el cambio climático, como al imperativo de adoptar una actitud de precaución ante el mismo. Además, las discusiones permitieron aumentar el número de ciudadanos que opinaba que combatir el cambio climático constituye una responsabilidad socialmente compartida, lo que llevó a un mayor reconocimiento de la necesidad de disminuir los niveles de consumo. Por lo que respecta a las medidas para hacer frente al calentamiento global, las de índole educativa fueron preferidas a las de carácter económico y normativo, pero lo que quizá reviste un mayor interés es el grado de generalidad de las acciones propuestas. En efecto, los participantes sugirieron acciones que no sólo sirven para mitigar el cambio climático, sino que también permiten afrontar otros retos ecológicos, sociales y económicos, lo que puede traslucir tanto una representación del calentamiento global en el marco de una crisis planetaria de naturaleza multidimensional, como un entendimiento holístico del concepto de medio ambiente. Veamos con mayor profundidad qué tipo de propuestas emana de la ciudadanía cuando se la interroga acerca de la mitigación del cambio climático y la adaptación al mismo.

\section{RESPUESTAS CIUDADANAS AL CAMBIO CLIMÁTICO: ALGUNAS PROPUESTAS FORMULADAS DESDE BARCELONA}

Se van a presentar algunos resultados parciales de una experiencia piloto de debate ciudadano focalizado en la definición de propuestas para combatir el cambio climático. El debate, conducido por geógrafos del Equipo de Investigación en Ecología Social y Planeamiento Participativo, del Departamento de Geografía Humana de la Universidad de Barcelona, se desarrolló en el marco de la Jornada sobre Cambio Climático y Crisis Energética: Soluciones Conjuntas, celebrada en Barcelona el 1 de diciembre de 2007 y organizada por el Observatorio de la Crisis Energética y las Alternativas de Sociedad (OCEAS).

La celebración de la jornada estuvo precedida por dos sesiones preparatorias en las que expertos provenientes de distintos ámbitos del saber trataron de establecer los principales retos en relación a cuatro grandes apartados temáticos con incidencia en el cambio climático: la producción agraria, las relaciones entre las escalas local y global, la gestión de los recursos hídricos y la crisis energética. La discusión permitió sentar unas mínimas bases de consenso que fueron recogidas en un documento inédito titulado Declaración sobre la crisis energética y el cambio climático. Creemos que este título anuncia el principal inconveniente del proceso, dado que se tendió a establecer una relación demasiado unívoca entre la crisis 
energética y el cambio climático. Aunque es insoslayable que ambos fenómenos están estrechamente vinculados, ni mucho menos son equivalentes, ya que la crisis energética es una problemática de naturaleza básicamente económica, motivada por la disminución de la oferta de petróleo, que provoca el progresivo agotamiento de los yacimientos.

Sea como sea, el trabajo realizado en las sesiones preparatorias se dio públicamente a conocer en la jornada anteriormente mencionada, a la que asistieron tanto científicos como ciudadanos sensibilizados por esas cuestiones. Como objetivo prioritario, este acto perseguía la generación de nuevos conocimientos a partir de la alianza entre expertos y ciudadanos. Joaquim Sempere et al. (2005: 102) han puesto de manifiesto que este tipo de coalición facilita la construcción de discursos amplios, unificadores y que tienden a llegar a la raíz de los problemas. A la vista de ello, en el marco de cada una de las cuatro sesiones de trabajo en las que se estructuró la jornada, se propuso a los asistentes que formularan y debatieran medidas para hacer frente al cambio climático. El resultado de la consulta -cuyos pormenores pueden encontrarse en Alió et al., 2008- es una lista de noventa y tres propuestas, cifra elevada que denota tanto el interés que suscitó la iniciativa como la existencia de un sólido conocimiento y sensibilidad ambiental entre los asistentes.

Más allá de la adscripción de las propuestas a cada sesión temática (Alió et al., 2008: 126-130), resulta muy interesante constatar cómo éstas pueden clasificarse según hagan referencia, de un lado, a la cultura ambiental, y de otro, al sistema tecnológico y su engarce con la producción, el consumo y el modelo territorial (Alió et al. 2009b).

Las primeras, que suponen un 49 por ciento del total de medidas propuestas, persiguen tres objetivos fundamentales. En primer lugar, diversas acciones están orientadas a incrementar el acervo de conocimientos sobre las causas y consecuencias del cambio climático. Los asistentes mostraron especial interés por fomentar la educación ambiental en las escuelas, así como por mejorar el conocimiento del conjunto de la población relativo a cuestiones mal comprendidas o valoradas, tales como el papel de la agricultura y del modelo alimentario mundial en las emisiones de GEI. Asimismo, se reconoció la necesidad de mejorar el conocimiento científico del cambio climático, para lo cual se propuso, entre otras medidas, reforzar los actuales mecanismos universitarios de interdisciplinariedad e, incluso, de transdisciplinariedad. Un segundo paquete de medidas referentes a la cultura ambiental busca aumentar la concienciación y sensibilización social respecto a la problemática, por ejemplo, mediante la difusión de campañas institucionales dirigidas a la ciudadanía y al tejido empresarial. Finalmente, se formularon varias propuestas encaminadas a promover la implicación ciudadana en la toma de decisiones políticas que atañan al cambio climático, 
reforzando tanto los mecanismos institucionales de participación social, como las formas ainstitucionales de mediación del público en los procesos de definición de estrategias políticas.

En cuanto a las propuestas relativas al sistema tecnológico, se reconoció de forma generalizada la necesidad de modificar los actuales patrones de consumo y producción de energía, pero también se atendió a otros elementos, como la agricultura y el agua. Respecto a la primera, se hizo énfasis en la potenciación de los mercados agrarios locales con el objetivo de reducir las emisiones vinculadas al transporte de alimentos. Resulta muy significativo que este tema aflorase en el debate, pues se trata de una cuestión que no acostumbra a suscitar un gran interés entre los medios de comunicación. Un estudio reciente ha demostrado que las elevadas tasas de obesidad en los países ricos generan unas emisiones extra de GEI que oscilan entre 0,44 y 0,98 gigatoneladas anuales equivalentes de $\mathrm{CO}_{2}$ (Edwards et al., 2009: 3). Este ejemplo revela que la cuota de participación de la agricultura en el calentamiento del planeta no es nada desdeñable, siendo, por tanto, muy pertinente que los ciudadanos crean que conviene adoptar medidas para cambiar el actual modelo de producción y consumo de alimentos.

En lo que al agua se refiere, las propuestas están encaminadas a restringir su consumo, lo que parece traslucir un reconocimiento de que el cambio climático implicará una disminución de la precipitación en nuestro entorno, un efecto sobre el que existen grandes incertidumbres científicas. En consecuencia, los asistentes no sólo formularon medidas de mitigación, sino que también contemplaron estrategias orientadas a la adaptación de la sociedad a las nuevas condiciones ambientales. Por último, se planteó un conjunto de medidas que tienen por objeto reducir la utilización de energía a través del planeamiento urbano y la planificación territorial. Se reconoció que la ciudad densa y compacta contribuye al ahorro energético, siendo, por tanto, preferible al modelo difuso, que incrementa las necesidades de movilidad. Asimismo, se hizo hincapié en la conveniencia de fomentar los medios de transporte alternativos al automóvil, tanto dentro de los espacios urbanos como a escala territorial.

Es posible establecer una segunda clasificación de las propuestas atendiendo a su grado de complejidad. Por un lado, se detectan medidas sencillas, que sugieren acciones directas, concretas y sectoriales; por otro, se advierten propuestas de carácter transversal, referidas a aspectos estructurales e imbuidas de una complejidad para la que el sistema político y económico no parece estar suficientemente maduro. Con todo, unas y otras, lejos de ser contradictorias, resultan perfectamente complementarias, y parecen apuntar a la dialéctica entre el modelo de control y el modelo preventivo que caracteriza a las políticas ambientales contemporáneas (Alió, 1999). 
Por último, no puede dejar de señalarse que durante las sesiones de debate afloraron ideas, conceptos y valores que la literatura científica y la práctica política suelen pasar por alto, pero que, pese a ello, merecen ser tomados en consideración. Así, por ejemplo, una de las propuestas apunta la posibilidad de planificar un decrecimiento económico para atenuar los efectos del cambio climático. Se trata de una medida que atenta contra el fundamento básico del sistema capitalista y cuyas posibilidades de ser llevada a la práctica se antojan ínfimas. Pero al menos tiene el mérito de abrir una vía de reflexión que puede conducir a conclusiones interesantes sobre la incompatibilidad ecológica de muchos de los principios que sustentan nuestro estilo de vida. En otro lugar ya se ha destacado el valor de las propuestas formuladas en Cataluña por las movilizaciones ciudadanas de carácter ambiental (Alió et al., 2009a). En efecto, ideas como la nueva cultura del agua o la prevención de la contaminación fueron primeramente planteadas "desde abajo», en el seno de grupos ciudadanos organizados para la consecución de un bien público, y posteriormente han sido integradas en el debate político y científico. Del mismo modo, durante la consulta sobre el cambio climático se formularon algunas propuestas que hoy por hoy parecen irrealizables, pero que quizá en un futuro no lo sean tanto, o que al menos merecen alguna reflexión.

Por tanto, esta iniciativa demuestra las potencialidades del diálogo social para hacer emerger diferentes alternativas de cara a afrontar uno de los mayores desafíos que la humanidad tiene planteados. En otras palabras, prueba que el ciudadano de a pie puede llegar a ser un agente activo en la producción del conocimiento.

\section{CONCLUSIÓN}

En este trabajo se ha tratado de mostrar que la magnitud y complejidad del reto planetario que supone hacer frente al cambio climático obligan a mantener una actitud abierta ante cualquier aportación, sea o no sea científica. La pluralidad de elementos interconectados y de perspectivas legítimas aconseja abordar las respuestas al cambio climático mediante enfoques transversales, que atiendan a las opiniones de los diferentes segmentos de población. El diálogo social se antoja, entonces, como indispensable para alcanzar un entendimiento profundo de las variables interrelacionadas de un problema que traspasa la tradicional división de las disciplinas científicas. Por otro lado, se ha examinado la percepción social del cambio climático, poniendo de relieve que la concienciación y conocimientos de la población al respecto han experimentado mejoras muy notables a lo largo de los últimos años. En consecuencia, el ciudadano parece capacitado para realizar aportaciones interesantes, por lo que sus puntos de vista deberían ser tomados en consideración por la comunidad científica y las autoridades políticas. 
Con todo, no nos atrevemos a confirmar con rotundidad la validez de la hipótesis que planteamos en la introducción. Ahí se dijo que el conocimiento que atesora el ciudadano podría producir resultados más fructíferos que los cosechados hasta ahora por científicos y políticos para hacer frente al calentamiento global. Aun siendo innegable que las actitudes ciudadanas ante este fenómeno encierran numerosos elementos sobre los que conviene reflexionar, y que la lucha contra el cambio climático, que de forma imperativa ha de tener un carácter socialmente compartido, exige la concertación de medidas entre los distintos agentes sociales, parece muy aventurado situar en un plano de igualdad el conocimiento científico y el conocimiento popular. Como se ha visto en el apartado dedicado a la representación social del cambio climático, todavía persisten algunas equivocaciones importantes, y a ello hay que añadir la poca predisposición de la sociedad a iniciar acciones que impliquen costes personales directos. No deben minusvalorarse las potencialidades del conocimiento ciudadano para combatir el cambio climático, pero tampoco hay que tener una fe ciega en la capacidad de los individuos para resolver el problema.

De todos modos, habrá que seguir indagando en el valor de las contribuciones ciudadanas y su capacidad para apuntar vías de reflexión que puedan conducir a soluciones de «altas miras». Se trata de un campo de investigación de amplio recorrido, sumamente interesante y al que la geografía puede realizar valiosísimas aportaciones.

\section{BIBLIOGRAFÍA}

Alıó, M. Àngels (1999): Contaminació i societat. Polítiques ambientals I. Publicaciones de la Universidad de Barcelona, Barcelona, 109 pp.

Alı́, M. Àngels y Jori, Gerard (2008): «Formulació ciutadana de propostes per a la transició energética», en CAPDEVILA, Laia, GÓMEZ, Aglaia y GÓMEZ, Daniel (Coords.): Canvi climàtic i crisi energética: solucions comunes. Generalitat de Catalunya, Barcelona, pp. 121-130.

Alió, M. Àngels y JoRı, Gerard (2009a): «La evolución reciente de las movilizaciones ambientales en Cataluña (1970-2007)», en FERIA TORIBIO, José $\mathrm{M}^{a}$, GARCÍA GARCÍA, Antonio y OJEDA RIVERA, Juan Francisco (Eds.): Territorios, sociedades y políticas. Universidad Pablo de Olavide, Sevilla, pp. 431-440.

Alió, M. Àngels y Jori, Gerard (2009b): «La sociedad civil ante la crisis energética: aportaciones al reto ecológico desde la ciudad de Barcelona», en Comunicaciones técnicas del $9^{\circ}$ Congreso Nacional del Medio Ambiente. Fundación CONAMA, Madrid, s/p. Disponible en CD-Rom [ISBN: 978-84-643-1481-2].

Barros, Vicente (2006): El cambio climático global. ¿Cuántas catástrofes antes de actuar? Libros del Zorzal, Buenos Aires, 174 pp. 
BeLl, Allan (1994): «Climate of opinion: public and media discourse on the global environment», en Discourse and Society, vol. V, no 1, pp. 33-64.

Boix Fayos, Carolina, Calvo Cases, Adolfo e Imeson, Antón C. (1999): «Implicaciones del cambio climático sobre los procesos geomórficos en el ámbito mediterráneo. Estado de la cuestión», en Cuadernos de Geografía, no 65-66, pp. 27-44.

Bord, Richard J., Fisher, Ann y O'Connor, Robert E. (1998): «Public perceptions of global warming: United States and international perspectives», en Climate Research, vol. XI, n⿳ 1 , pp. 75-84.

Boyes, E. y Stanisstreet, M. (1993): «The 'Greenhouse Effect': children's perceptions of causes, consequences and cures», en International Journal of Science Education, vol. XV, nº 5, pp. 531-552.

BRENCHI, Steven R. (2003): «Comparative public opinion and knowledge on global climatic change and the Kyoto Protocol: the U.S. versus the world?», en International Journal of Sociology and Social Policy, vol. XXIII, no 10, pp. 106-134.

Burgess, J., Harrison, C. M. y Filius, P. (1998): «Environmental communication and the cultural politics of environmental citizenship», en Environment and Planning A, vol. XXX, no 8, pp. 1.445-1.460.

Camarasa Belmonte, Ana Ma y Moreno Sanz, Fernando (1994): «Algunas reflexiones sobre la percepción del cambio climático en una muestra de población adulta de nivel cultural medio», en Serie Geográfica, vol. IV, pp. 127-132.

CAPEl, Horacio (1973): «Percepción del medio y comportamiento geográfico», en Revista de Geografía, vol. VII, n 1-2, pp. 58-150.

CaPel, Horacio (1980): «Organicismo, fuego interior y terremotos en la ciencia española del siglo XVIII», en Geo Crítica, Cuadernos Críticos de Geografía Humana, no 27-28, pp. 5-94.

Centro de Investigaciones Sociológicas (2007): Ecología y medio ambiente (III). Estudio $n^{\circ}$ 2682. Centro de Investigaciones Sociológicas, Madrid, s/p. En línea: http://www.cis.es/cis/opencm/ES/1_encuestas/estudios/ver.jsp?estudio=8160 [23 de mayo de 2009].

CMNUCC (1992): Convención marco de Naciones Unidas sobre el cambio climático. Naciones Unidas, Nueva York, 26 pp.

CMNUCC (1998): Protocolo de Kioto de la Convención marco de Naciones Unidas sobre el cambio climático. Naciones Unidas, Nueva York, 24 pp.

Comisión Europea (2007): Libro verde de adaptación al cambio climático en Europa: opciones de adaptación para la UE. Unión Europea, Bruselas, 29 pp.

Deines, Tina (2007): Global warming coverage in the media: trends in a Mexico City newspaper. Kansas State University, Manhattan, KS, 121 pp.

Departament de Medi Ambient i Habitatge (2008): Pla marc de mitigació del canvi climàtic a Catalunya 2008-2012. Generalitat de Catalunya, Barcelona, 90 pp. 
DisPensa, Jaclyn Marisa y Brulle, Robert J. (2003): «Media's social construction of environmental issues: focus on global warming. A comparative study», en International Journal of Sociology and Social Policy, vol. XXIII, n 10, pp. 74-105.

Dunlap, Riley E. (1998): «Lay perceptions of global risk. Public views of global warming in cross-national context», en International Sociology, vol. XIII, nº 4 , pp. 473-498.

EDwards, Phil y Roberts, Ian (2009): «Population adiposity and climate change», en International Journal of Epidemiology, Advance Access, pp. 1-4.

Escudero Gómez, Luis Alfonso (2008): «Una verdad incómoda, una amenaza mundial y una cuestión moral. Reflexiones geográficas para el fin del debate del cambio climático y una propuesta de compromiso ante el riesgo medioambiental», en Actas del X Coloquio Internacional de Geocrítica. Universidad de Barcelona, Barcelona, s/p. En línea: http://www.ub.es/geocrit/-xcol/36.htm [21 de mayo de 2009].

European Commission (2003): Second ECCP progress report. Can we meet our Kyoto targets? European Union, Brussels, 73 pp.

European Commission (2008): Attitudes of European citizens towards the environment. European Union, Brussels, 75 pp.

Feldmann, Fabio José y Biderman Furriela, Rachel (2001): «Los cambios climáticos globales y el desafío de la ciudadanía planetaria», en Acta Bioethica, vol. VII, no 2, pp. 287-292.

Feyerabend, Paul K. (2002 [1975]): Contra el método. Esquema de una teoría anarquista del conocimiento. Folio, Barcelona, 189 pp.

Fundación BBVA (2008): Percepción y actitudes de los españoles hacia el calentamiento global. Grupo BBVA, Madrid, 45 pp. En línea: http://www.fbbva.es/ TLFU/dat/presentacion_calentamiento_global.pdf [23 de mayo de 2009].

Funtowicz, Silvio O. y Ravetz, Jerry R. (1991): «A new scientific methodology for global environmental issues», en COSTANZA, Robert (Ed.): Ecological economics: the science and management of sustainability. Columbia University Press, New York, pp. 137-152.

Funtowicz, Silvio O. y Ravetz, Jerry R. (1999): «Política ambiental en situacions de complexitat», en Medi Ambient, Tecnologia i Cultura, no 24, pp. 71-74.

[The] Gallup Organisation (2007): Attitudes on issues related to EU Energy Policy. European Union, Brussels, s/p.

Githeko, Andrew K., Lindsay, Steve W., Confalonieri, Ulisses E. y Patz Jonathan A. (2000): «Climate change and vector-borne diseases: a regional analysis», en Bulletin of the World Health Organization, vol. LXXVIII, no 9, pp. 1.136-1.147.

Gómez Martín, Ma Belén (2005): «Reflexión geográfica en torno al binomio climaturismo», en Boletín de la Asociación de Geógrafos Españoles, nº 40, pp. 111-134. 
Habermas, Jürgen (1988): Ensayos políticos. Península, Barcelona, 283 pp.

Hersch, Joni y Vuscusi, W. Kip (2006): «The generational divide in support for environmental policies: European evidence», en Climatic Change, vol. LXXVII, no 1-2, pp. 121-136.

IPCC. Cambio climático 2007: Informe de síntesis. Contribución de los Grupos de trabajo I, II y III al Cuarto informe de evaluación del Grupo intergubernamental de expertos sobre el cambio climático. OMM y PNUMA, Ginebra, 103 pp.

Kane, Sally y Shogren, Jason F. (2000): «Linking Adaptation and Mitigation in Climate Change Policy», en Climatic Change, vol. ILV, no 1, pp. 75-102.

Kasemir, Bernd, Behringer, Jeannette, Marchi, Bruna de et al. (s/f.): UlYSSES. Urban Lifestyles, Sustainability and Integrated Environmental Assessment. Working Paper. Darmstadt University of Tecnology, Darmstadt, 89 pp.

KASEMIR, Bernd (2001): «Improving procedures for citizen participation and stakeholder involvement», en Social sciences for knowledge and decision making. OECD Publishing, Paris, pp. 129-133.

Kempton, Willet M. (1991): «Lay perspectives on global climate change», en Global Environmental Change, vol. I, no 3, pp. 183-208.

Kempton, Willet M. (1993): «Will public environmental concern lead to action on global warming?», en Annual Review of Energy and the Environment, vol. XVIII, no 1 , pp. 217-245.

LaCey, Collin y Longman, David (1997): The press as public educator. Cultures of understanding, cultures of ignorance. University of Luton Press, Luton, $336 \mathrm{pp}$.

Leiserowitz, Anthony (2006): «Climate change risk perception and policy preferences: the role of affect, imaginary and values», en Climatic Change, vol. LXXVII, no $1-2$, pp. 45-72.

Lorenzoni, Irene y Pidgeon, Nick F. (2006): «Public views on climate change: European and USA perspectives», en Climatic Change, vol. LXXVII, n ${ }^{\circ} 1-2$, pp. 73-95.

MARTín-Vide, Javier (1990): «La percepción del clima en las ciudades», en Revista de Geografía, vol. XXIV, nº 1-2, pp. 27-33.

Martín-Vide, Javier (1999): Fundamentos de climatología analítica. Síntesis, Madrid, $157 \mathrm{pp}$.

MARTín-Vide, Javier (2001): «Algunas reflexiones y ejemplos del valor de la percepción ambiental en la planificación territorial y de actividades», en Revista de Desenvolvimento Económico, no 4, pp. 60-64.

MARTín-Vide, Javier (2008): «La nueva realidad del calentamiento global. Un decálogo del cambio climático», en Scripta Nova, Revista Electrónica de Geografía y Ciencias Sociales, vol. XII, no 270(23), s/p. En línea: http://www.ub.es/geocrit/sn/sn-270-23.htm [19 de mayo de 2009]. 
Meira Cartea, Pablo Ángel y Arto Blanco, Mónica (2008): «La representación del cambio climático en la sociedad española. De la conciencia a la acción», en Seguridad y Medio Ambiente, 2008, n 109, pp. 31-47.

Meira Cartea, Pablo Ángel (Dir.), Arto Blanco, Mónica y Montero Souto, Pablo (2009): La sociedad ante el cambio climático. Conocimientos, valoraciones y comportamientos en la población española. Fundación Mapfre, Madrid, 181 pp.

Ministerio de Medio Ambiente. Estrategia española de cambio climático y energía limpia. Horizonte 2007-2012-2020. Gobierno de España, Madrid, 52 pp.

OlCina Cantos, Jorge y MarTín-Vide, Javier (1999): La influencia del clima en la historia. Madrid: Arco Libros, 96 pp.

Olcina Cantos, Jorge (2009): «Percepción de los cambios del clima a lo largo de la historia», en ALBEROLA, Armando y OLCINA CANTOS, Jorge (Eds.): Desastre natural, vida cotidiana y religiosidad popular en la España moderna y contemporánea. Publicaciones de la Universidad de Alicante, Alicante, pp. 433-470.

Olson, Mancur. The Logic of collective action. Public goods and the theory of groups. Harvard University Press, Cambridge, MA, 186 pp.

Poortinga, Wouter; Pidgeon, Nick y Lorenzoni, Irene (2006): Public perceptions of nuclear power, climate change and energy options: summary findings of a survey conducted during October and November 2005. Working Paper. University of East Anglia, Norwich, 56 pp.

Read, Daniel; Bostrom, Ann; Morgan, M. Granger; Fischhoff, Baruch y Smuts, Tom (1994a): «What do people know about global climate change? 1. Mental models», en Risk Analysis, vol. XIV, nº 6, pp. 959-970.

Read, Daniel; Bostrom, Ann; Morgan, M. Granger; Fischhoff, Baruch y Smuts, Tom (1994b): «What Do People Know About Global Climate Change? 2. Survey Studies of Educated Laypeople», en Risk Analysis, vol. XIV, nº 6, pp. 971-982.

Rodríguez, R.; Barriendos, M.; Jones, P. D.; Martín-Vide, J. y Peña, J. C. (2001): «Long pressure series for Barcelona (Spain). Daily reconstruction and monthly homogenization», en International Journal of Climatology, 2001, n 21, pp. 1.693-1.704.

Rodríguez Díaz, J. A.; Knox, J. W. y Weathherhead, E. K. (2006): «Uso del indicador agroclimático PSMD para la representación y evaluación del impacto del cambio climático en las necesidades del agua de riego en España», en Ingeniería del Agua, vol. XIII, no 4, pp. 311-320.

Rosas, Carlos Alberto (2002): «Sumideros de carbono: ¿solución a la mitigación de los efectos del cambio climático?», en Ecosistemas, Revista Científica y Técnica de Ecología y Medio Ambiente, no 3, s/p. En línea: http://rua.ua.es/dspace/ bitstream/10045/9101/1/ECO_11\%283\%29_22.pdf [19 de mayo de 2009]. 
SAuer, Carl O. (2005 [1995]): «La acción del hombre sobre la Tierra», en NAREDO, José Manuel y GUTIÉRREZ, Luis (Eds.): La incidencia de la especie humana sobre la faz de la Tierra (1955-2005). Universidad de Granada, Granada, pp. 413-447.

Semperez, Joaquim (Dir.), Rodríguez, Roser y TorRents, Jordi (2005): El paper dels experts en els moviments ambientalistes a Catalunya. Fundació Jaume Bofill, Barcelona, 179 pp.

SLuijs, Jeroen PP. van der (2002): «ULYSSES (Urban Lifestyles, Sustainability and Integrated Environmental Assessment)», en TOLBA, Mustafa K. (Dir.): Encyclopaedia of Global Environmental Change. Vol. IV: Responding to Global Environmental Change. John Wiley \& Sons, Chichester, p. 460.

Sustein, Cass R. (2006): «The availability heuristic, intuitive cost-benefit analysis, and climate change», en Climatic Change, vol. LXXVII, no 1-2, pp. 195-210.

TÀBARA, Joan David (2000): «Parlem del clima. Aportació de la sociologia qualitativa a l'Avaluació Integrada del canvi climàtic», en Revista Catalana de Sociologia, $\mathrm{n}^{\circ} 13$, pp. 45-76.

TÀBARA, Joan David (2003): «Participación cualitativa y evaluación integrada del medio ambiente y de la sostenibilidad. Aspectos metodológicos en cuatro estudios de caso», en Documents d’Anàlisi Geogràfica, no 42, pp. 183-213.

TÀBARA, Joan David (2005): «Percepció i comunicació sobre el canvi climàtic», en LLEBOT, Josep Enric (Ed.): Informe sobre el canvi climàtic a Catalunya. Generalitat de Catalunya, Barcelona, pp. 773-815.

TÀBARA, Joan David (Coord.) (2008): Percepció pública i política del canvi climàtic a Catalunya. Generalitat de Catalunya, Barcelona, 115 pp.

[La] Vanguardia. Hemeroteca de La Vanguardia desde 1881. La Vanguardia Ediciones, Barcelona, s/p. En línea: http://www.lavanguardia.es/hemeroteca/ [21 de mayo de 2009].

WeART, Spencer (2006): El calentamiento global. Historia de un descubrimiento científico. Universidad Pública de Navarra-Laetoli, Pamplona, 260 pp.

Weber, Elke U. (2006): «Experience-based and description-based perceptions of long-term risk: why global warming does not scare us (yet)», en Climatic Change, vol. LXXVII, no 1-2, pp. 103-120.

Zanirato, Silvia Helena (2008): «Desafios para a conservação do patrimônio da humanidade diante das mudanças climáticas», en Actas del X Coloquio Internacional de Geocrítica. Universidad de Barcelona, s/p. En línea: http://www. ub.es/geocrit/-xcol/378.htm [20 de mayo de 2009]. 